\title{
Pandemics: Historically Slow "Learning Curve" Leading to Biomedical Informatics and Vaccine Breakthroughs
}

\author{
Casimir A. Kulikowski \\ Department of Computer Science, Rutgers University, USA
}

\begin{abstract}
Summary
Background: The worldwide tragedy of the severe acute respiratory syndrome coronavirus 2 (SARS-CoV-2) pandemic vividly demonstrates just how inadequate mitigation and control of the spread of infectious diseases can be when faced with a new microorganism with unknown pathogenic effects. Responses by governments in charge of public health, and all other involved organizations, have proved largely wanting. Data infrastructure and the information and communication systems needed to deal with the pandemic have likewise not been up to the task. Nevertheless, after a year of the worldwide outbreak, hope arises from this being the first major pandemic event in history where genomic and related biosciences - relying on biomedical informatics - have been essential in decoding the viral sequence data and producing the mRNA and other biotechnologies that unexpectedly rapidly have led to investigation, design, development, and testing of useful vaccines. Medical informatics may also help support public health actions and clinical interventions - but scalability and impact will depend on overcoming ingrained human
\end{abstract}

shortcomings to deal with complex socio-economic, political, and technological disruptions together with the many ethical challenges presented by pandemics.

Objectives: The principal goal is to review the history of biomedical information and healthcare practices related to past pandemics in order to illustrate just how exceptional and dependent on biomedical informatics are the recent scientific insights into human immune responses to viral infection, which are enabling rapid antiviral vaccine development and clinical management of severe cases - despite the many societal challenges ahead. Methods: This paper briefly reviews some of the key historical antecedents leading up to modern insights into epidemic and pandemic processes with their biomedical and healthcare information intended to guide practitioners, agencies, and the lay public in today's ongoing pandemic events. Conclusions: Poor scientific understanding and excessively slow learning about infectious disease processes and mitigating behaviors have stymied effective treatment until the present time. Advances in insights about immune systems, genomes, proteomes, and all the other -omes, became a reality thanks to the key sequencing technologies and biomedical informatics that enabled the Human Genome Project, and only now, 20 years later, are having an impact in ameliorating devastating zoonotic infectious pandemics, including the present SARS$\mathrm{CoV}-2$ event through unprecedently rapid vaccine development. In the future these advances will hopefully also enable more targeted prevention and treatment of disease. However, past and present shortcomings of most of the COVID-19 pandemic responses illustrate just how difficult it is to persuade enough people - and especially political leaders - to adopt societally beneficial risk-avoidance behaviors and policies, even as these become better understood.

\section{Keywords}

Pandemic histories, slow biomedical learning curve, immunology and vaccines, SARS-CoV-2, genomic epidemiology, biomedical and public health informatics, ethics

Yearb Med Inform 2021:290-301

http://dx.doi.org/10.1055/s-0041-1726482

\section{The Excessively Slow Human "Learning Curve" in the History of Pandemics}

From the earliest technology of written records to today's sophisticated web-based biomedical sciences and technologies, humans have dealt poorly with the largely unexplainable and frequently unexpected scourge of epidemic and pandemic spreads of infectious diseases. Tales from ancient times from all the world describe suffering, death, and traumatized survival but contain little clear useful information about how physicians or other healers dealt effectively with plagues. Only in the past 300 years have sciences, technologies, and practices of medical, nursing, and epidemiological public health gradually developed sufficiently to help understand and manage epidemics and pandemics rationally. Yet, individual vaccination and hygienic practices, as well as effective adherence to preventive societal behavioral norms continue to fall short in containing the myriad of unpredictably virulent zoonotic infections that plague human populations. This is largely because of deep and widespread ignorance, misunderstanding, and misinformation about the rapidly evolving complex and changing ecologies of mutation-prone micro-organisms including those in symbiotic microbiomes and co-existing species despite increased biomedical awareness and understanding of these problems over recent decades [1].

\section{Early Historical Information on Pandemics}

The specific effects of illnesses - including infectious, inflammatory, and recognizably chronic conditions - can be traced to approximately 2,500 years ago when we begin to read in the surviving written sources how Hippocrates gives in the book "Of the 
Epidemics" a detailed, reasoned account of clinical observations of the effects of what appears to be epidemic outbreaks on islands just off the coast of his native Ionia. He also was the first to recognize how symptoms appear to be contagious from person to person - strikingly among athletes in close proximity to each other while wrestling in gymnasia. In contrast, in earlier Homeric literature, and for Greek authors before Hippocrates, epidemic simply meant "who is in his country" from epi=on and demos=people. So, Hippocrates was the first to have used the word epidemic with the modern medical meaning of a "set of syndromes occurring in a given place for a given period" $[2,3]$.

Thucydides is the first historian to describe a sequence of transmission from distant and exotic lands to Greece, and through its port of Piraeus to Athens, when he eloquently describes the great plague that ravaged the city and killed Pericles during the siege by the Spartans in the history of the Peloponnesian War [4]. He tells of the early attempts by physicians to care for the infected, but later abandoning patients once they were unable to help, and the incredibly large death toll estimated at $25 \%$ of the population of the city. This led to the disintegration of social order with crime and misbehavior running rampant, and the abandoning of ritual funerals, so that bodies of the dead were either left where they fell, or just thrown into piles on one another, and burnt [5]. References to plagues and pestilences can be found in many other and even earlier sources, such as the Bible and other records from the Near and Middle East $[6,7]$, as well as from India and China. Related to potential pre-historic origins, a recently posted as yet unreviewed pre-print reporting on comparative genomic studies conjectures that a corona virus-like epidemic may have driven adaptation in East Asian populations from 25,000 to 5,000 years ago [8]. However, little recorded information has survived about the ways in which people systematically and medically coped with such disasters beyond minor palliatives for suffering, and praying to gods to save them from the incomprehensible waves of invisibly caused illness, death, and destruction.

Western medicine has been largely influenced by Greek Hippocratic medicine as transmitted through Roman sources that built on the traditions of Herodotus, the "father of history", who included many medical accounts and stories in his writings [9]. Hippocrates was the first to wean medicine from the biases of Olympian religious beliefs which led people to think about the causes and healing of maladies in terms of godly interventions in the earlier Asclepian tradition [10]. In contrast, Hippocrates resorted mostly to empirical remedies for a wide range of illnesses based on reasoned interpretations of observations about patients, also developing precepts of minimal treatment: to do the least harm with medical interventions in the natural course of disease. These have immortalized his name for posterity when the Hippocratic Oath for physicians became gradually accepted as the standard for ethical behavior in clinical matters $[11,12]$. The empirical and rational Ionian school of medicine was an innovative and challenging departure from the previous highly interventionist medical philosophies that had developed from the anatomically informed and sophisticated Egyptian medical practices which were often surgical, and which most commonly were followed in Greece before and during the time of Hippocrates, and interpreted in religious terms [13].

The Hippocratic sources include discussions about the role of environmental conditions such as humidity and "miasmas" in the air coming from natural swamp environments (common in the days before extensive drainage projects) or, during epidemics, from putrefaction of corpses, and blamed these as the cause of contagion [14]. This was explained through the contemporary theories of "humors" involving the flow of different types of fluids and gases within and through the bodies of individuals, which were assumed to be essential to the maintenance of life, and which, when badly disrupted or unbalanced, were thought to cause illnesses. Person-to-person contact as a factor in epidemic spread is mentioned by Thucydides in his book on the Peloponnesian Wars, but it is conflated with religious contamination, following the traditional thinking. While crowding in cities is mentioned by him during the siege of Athens, it was not explicitly noted as a possible factor in epidemic spread, even though lifestyle, diet, and exercise are mentioned frequently in Greek medicine as impacting health and maintaining balance between the various bodily humors. On the other hand, malnutrition was recognized as an important factor in increasing the vulnerability of people to disease. Lung diseases, including pneumonia, pleurisy, coughs, and colds as well as declining, consumptive physical conditions, and skin lesions, often come up in the Hippocratic writings, as does leprosy, infections of the liver, digestive disorders due to parasites, diarrheas, kidney and bladder conditions, and eye infections such as conjunctivitis and trachoma, as well as glaucoma $[13,15]$. Modern interpretations of what might have been the causal infectious agents behind the great Plague of Athens based on the descriptions in Thucydides include Yersinia pestis, typhus, typhoid, and Ebola or some other infection leading to a viral hemorrhagic fever. Results from DNA (deoxyribonucleic acid) analysis of material taken from teeth in mass burials from the pandemic period detected the presence of Salmonella enterica, supporting a typhoid fever hypothesis [16]. The reported black fluid exuding from the bodies of the infected, the frequent contagion of those caring for the sick, the relative lack of infections among the besieging Spartans outside the long walls that connected Athens to its port of Piraeus, as well as indications that central African monkeys had been imported at the time with the enormous quantities of ivory needed for the Pallas Athena statue in the Parthenon, all suggest the plausibility of an Ebola-like causative agent, though this has been impossible to prove due to non-survivability of RNA (ribonucleic acid) viral material [17].

During the Hellenistic period, extant sources suggest that Hippocratic innovative medical investigations and practices came mainly from Alexandria in Egypt, which produced a wealth of medical and surgical scholarship. After the Roman conquests of Greece and the Middle East, the Greek physician and philosopher Galen (who became the personal doctor to the emperor Marcus Aurelius) wrote extensive medical treatises within the Hippocratic tradition, adding considerable clinical observation of specific diseases. His work became the basis for much subsequent medical knowledge through the Middle Ages and beyond. He 
wrote about the Antonine Plague that spread throughout the empire and Rome itself, and which is now considered to have most likely been smallpox [18]. The next major plague across the Roman Empire during its crisis of usurpations and invasions during the third century is now argued to have been caused by an Ebola-like virus [19]. The Justinianic Plague due to Yersinia pestis was the next extensive pandemic that came from Africa and the East, and led to so much death, war, and destruction, that it has traditionally been considered a major cause of the depopulation of the Roman and Persian empires (deaths amounting to at least $30 \%$ or more of the populations), contributing to the disintegration of civil societies, decimation of armies, and subsequent conquest of much of the Middle East by Islam [20], then becoming endemic, and in a subsequent wave contributing to the fall of the Umayyad Caliphate [21]. Recent phylogenetic reconstructions suggest that multiple variants of $Y$. pestis spread across Western Europe [22], while other genomic analyses of remains from contemporaneous burials have downplayed the significance of the pandemic [23]. The surviving Eastern or Byzantine Empire reorganized healthcare in its cities and gave rise to the first hospitals [24]. These practices transferred to the Latin Western Europe and were the precursors within a Christian healing tradition of modern hospitals [25]. Yet, despite advances in healthcare, little new knowledge was available to deal with the greatest pandemic of all time that came from the East during the Middle Ages, which saw the spread of the Black Death or bubonic and pneumonic plagues caused by Y. Pestis, carried by fleas from rats and humans. The Black Death is estimated to have killed more than a third of the population of Europe, and continued to be endemic with repeated outbreaks until the early $19^{\text {th }}$ Century throughout most regions of the world [26]. Cohn [27] tells of how "physicians now directed their plague writings to the prince and discovered their most 'valiant remedies' in public health: strict segregation of the healthy and ill, cleaning streets, latrines, and addressing the long term causes of plague - poverty. Those outside the medical profession joined the chorus. Relying on health board statistics and dramatized with eyewitness descriptions of bizarre happenings, human misery, and suffering, they created the structure for the plague classics of the eighteenth century and by tracking the contagion's complex and crooked paths anticipated trends of nineteenth century epidemiology". That people living in poverty would frequently be blamed for disease due to their abject and insalubrious living conditions, unsanitary practices, and the contempt with which they were held by most of the powerful and the educated who wrote about these matters is emphasized in [28]. Another major scourge, smallpox, was a pandemic disease already recognized in ancient Egypt around 1,000 BCE [7], which, becoming endemic throughout the Mediterranean and all of Europe, was much later transmitted by Europeans to the Americas, ravaging the pre-conquest populations and facilitating the colonization and control of the "New World" continents [29].

\section{Gradual Progress in Understanding Immunological and Epidemiological Processes in the Modern Era}

From the $16^{\text {th }}$ to the mid- $19^{\text {th }}$ centuries, gradual but steady, and occasionally quite unexpected notable advances in the sciences and technologies for medicine took place. These advances were based on the observation of natural phenomena and experimentations in order to test theories generalizing the applicability of insights about diseases in general, epidemics in particular, and the effectiveness of a few of the highly empirical treatments tested. Rational and causal explanations of physical and biological phenomena slowly helped develop better understanding of physics, chemistry, and some of the basics of life and its processes. The underlying causes of epidemic and pandemic disease based on "germ theory" [30], however, were not uncovered until the $19^{\text {th }}$ century, when improved microscopes and more sophisticated methods of investigation led to a rapid succession of discoveries that still provide the major foundations for the understanding of microorganisms and their role in epidemiology.
But it was the purely empirical observations of relative immunity to smallpox (variola in Latin), in milkmaids who had contracted the related cowpox viral infection, that had inspired Jenner in 1796 to experiment with a variant of the older practice of "variolation" which had been used in China, India and the Middle East since before the 16th century and been experimented with in England and its North American colonies since the early 18th century [31]. Variolation consisted of the transfer from individuals who had been infected with smallpox of the powdered scab material or the fluid from pustules into superficial scratches made in the skin of others who hoped to receive immunity this way without contracting a serious or fatal case of the disease. Unfortunately, the procedure required much care in titrating the amounts of material transferred - and much luck in not transferring too much so as to produce a full-blown case of smallpox. By transferring the skin material from a different but apparently related infection and seeing its repeated success in protecting against severe cases of smallpox, despite considerable resistance from the medical profession of the day, the efficacy of the new vaccination method became recognized. Jenner's persistence paid off in the U.K. and led to the introduction of vaccination programs which became accepted around the world and named after the cows that when milked transmitted the cowpox to the maids, even though it is likely that the cows may have contracted the virus from horses [32].

Throughout the 19th century, scientists sought a better understanding of the causes of infectious diseases, which was not achieved until Louis Pasteur's research showed that the growth of micro-organisms was responsible for spoiling beverages, such as beer, wine, and milk, leading him to invent the process that bears his name: pasteurization, which kills most bacteria and molds in liquids by heating to between 60 and $100{ }^{\circ} \mathrm{C}$ [33]. He collaborated with Claude Bernard, the preeminent physiologist who introduced the scientific method in medicine, including blind trials for testing proposed interventions. In a number of fermentation experiments, Pasteur showed that contamination with microorganisms was required for fermentation - refuting 
the prevailing concepts of spontaneous generation, and suggesting that contamination by "germs" could cause infections in animals and people, inspiring Lister to propose and develop antiseptic procedures in surgical practice. Pasteur was a tireless investigator and went on to discover the causes and treatments of chicken cholera, swine erysipelas, and rabies, all of which were frequently fatal endemic zoonotic maladies from close contact of humans with farm animals and pets. He conducted daring experiments testing a vaccine for anthrax using the saliva of rabid dogs, and got into heated disputes with Robert Koch, the discoverer of anthrax bacteria on issues of vaccine preparation and contamination.Towards the end of the 19th century, scientists gradually began to develop an understanding of the mechanisms of immune inflammatory responses to viral infection. An article in the journal Cell [34] discusses these historical advances in bioscience, which accelerated dramatically throughout the 20th century, leading to the genomic revolution enabling investigation and tracking of zoonotic epidemic and pandemic transmission processes within and between species through their interactions in a wide range of shared environments.Metchnikoff in the 1880's carried out experiments with starfish observing the recruitment of mobile (immune) cells to the site of an induced injury, while Ehrlich around this same time was theorizing about how plasma cells with "side chains" (now known to be unique proteins) could attach themselves to specific types of viruses and "consume them" - phagocytosis. Von Behring and Shibasaburo's experiments tested how immunity to toxins and venoms might arise from serum producing an "antitoxin", while Ehrlich coined the word "antibody" to describe the chemical substance released into the bloodstream by cells in response to the invading "antigens" from microbes. It took until the 1940's for the Danish physiologists Bjorneboe and Gormsen to discover that it was white blood B-cells, originating in the bone marrow, which corresponded to one type of antibody. Another type of cell, named a "T-cell" from their origin in the thymus, were discovered to be the "killers" of virally infected cells which they accomplish by breaking into a cell, and introducing toxins into the cell interior. Burnett later proposed that clonal proliferation of a cell line selected by an antigen could explain the antibody response. In the 1970's it was shown in mouse experiments that T-cells first check to see whether an infected cell belongs to itself, whether the infection is viral or bacterial and only then goes about killing it. Detecting "self" is accomplished via a major histocompatibility complex (MHC) Class I protein which serves as a carrier enabling the detection of viral peptides (small fragments of a viral protein). A special type of $\mathrm{T}$ cell - the CD4 T or "helper" cell - provides yet another pathway for controlling infection by stimulating $B$ cells to synthesize antibodies, while dendritic cells present antigens to $T$ cells and initiate an immune response. All these are part of the adaptive immune system which attacks specific pathogens, while an evolutionarily older innate system uses immune system dendritic cells and macrophages to combat pathogens less specifically through toll-like receptors or TLRs. TLRs recognize molecular patterns corresponding to more general classes of pathogens. Interferons and other chemicals are released once a pattern has been recognized, and serve as preliminary anti-viral responders.

The above mechanisms can be interpreted through the metaphor of "cells-as-factories". Viruses, with a rare exception, do not have bacterial-like virulence factors or toxins. Being intracellular, viruses disrupt the body's function either by direct destructive effect on target cells and organs or by inducing pathogenic host responses. The cell can be looked on as a factory. A virus may use up the cell's energy; shut off the synthesis of required materials; compete for the cell's ribosomes, which are necessary for building proteins; or compete for the cell's polymerases and inhibit its innate defense system. Some viruses have the capacity to integrate into the cell's genome and thus cause indirect damage, leading, for instance, to malignancy - for which immunotherapies are increasingly effective [35]. As with bacterial virulence, the factors responsible for the intensity of viral infection affect both zoonotic and non-zoonotic agents [36].

About 20 years ago, the severe acute respiratory syndrome coronavirus (SARS$\mathrm{CoV}$ ) epidemic [37] was the first event producing specific genomic information relevant to the current COVID-19 pandemic. Researchers at the time were the first to benefit from the recently completed Human Genome Project - which had critically relied on advances in biomedical informatics - to achieve rapid human and animal genome sequencing with chronological changes indicating mutations in viral strains. This led to identifying the pathways of zoonotic virus transmission and pathogenesis as the epidemic spread [38]. A novel coronavirus resulting from several independent zoonotic strains was implicated in human cases, and hospitals were found to be among the epicenters for super-spreading events, with travelers transmitting the virus from mainland China to Hong Kong, Taiwan and Vietnam, and then globally. Civets and raccoon dogs sold in open markets were identified as likely reservoirs for human infection, and closure of markets helped suppress the expanding outbreak relatively quickly [39].

\section{The SARS-CoV-2 Pandemic and Biomedical and Health Informatics}

Biomedical informatics, a field of computer-based technological and scientific endeavor that has existed for little over half a century, has been the essential catalyst for advanced biomedical research with a major impact through the US National Library of Medicine's online computer-based literature and data resources [40], and those of its National Center for Biotechnology Information [41] which made the results of the Human Genome Project freely and openly available to the public worldwide, thereby significantly accelerating genomic, proteomic, and other molecular science data and information through its extensive informatics infrastructure. The viral pandemics of the present century, then, are the first where methods of data-and-knowledge intensive biomedical, healthcare, and public health informatics are all available to support the monitoring, analysis, modeling, and management of strategies being developed and deployed for both clinical and epidemiological purposes, making informatics a "critical strategy" for helping in the control of the present COVID-19 pandemic [42]. 
From a clinical perspective, most published literature describes early attempts to gather data and monitor the progression of the pandemic and its effect on hospital settings. It is still very tentative and primarily suggestive about the many telemedicine implementations with which informatics can help significantly augment, or when possible even replace, in-person clinical consultations that are risky to patients and practitioners alike, and more generally to assess the technological informatics support needed by hospitals, clinics, and other healthcare practices. Some aspects of using information technology in the first reported site of the pandemic in Wuhan, China, are described in [43], emphasizing the rapid deployment of shelter hospitals specifically designed to take in the patients with COVID-19, equipped with information exchange and electronic health record capabilities to deal with the need to deploy electronic capabilities and communication for healthcare practitioners managing the many emergency admissions of infected patients. Few details are given, however, of the specific systems' capabilities and deployment strategies, other than general references to the needs for physicians and managers to carry out monitoring, assessment of the distribution, severity, testing and tracing, and clinical care of the patients - with privacy issues of the latter also mentioned. During the Ebola (2014) and Zika (2015) epidemics, where risk communication and management were critical, researchers associated with the World Health Organization (WHO) noted a "subtle retreat of national agency" [44] when international guidance was obtained. However, in the present pandemic, there has been a reversal of this trend. All countries have managed their national emergencies differently according to the political, economic, social, and legal constraints of their own societies. The great variability in genetic pools, environments, and resources together with highly contrasting historical experiences, cultural predispositions, and wealth-health divides have all contributed to radically different and often hard-to-explain infection control patterns around the world. The World Health Organization has modified and expanded its International Classification of Disease (ICD) coding in order to keep track of numerous and rapid changes in medical knowledge and practice, including those for communicable disease outbreaks. However, the many required changes appear to have difficulty in keeping up with the rise of so many novel organisms that can cause pandemics, as witnessed by the ongoing addition of emergency codes as well as country-specific coding exceptions [45]. This adds complications to the efforts at regularizing coding and their knowledge bases by various standards-setting organizations such as HL7 FHIR, which has had to cope with the difficulties in switching from ICD-9 to the current ICD-10 (and the developing ICD-11) codes, which are distinct coding schemes [46]. Since epidemiological studies depend so critically on consistency mappings between standards for codes, the reported difficulties already experienced by changing coding practices due to mandatory adoption of ICD-10 codes [47] need to be recognized as a serious vulnerability of all clinical records and informatics systems that substantially impacts the analyses of pandemic trends and outcomes. There is also the evident danger of misclassifications in recorded patient histories essential for follow-up care of patients recovering from infection.

Despite the considerable and rapid increase in knowledge about infectious disease mechanisms at the cellular and molecular levels in the past years, Mukherjee, who started his career as an immunologist - emphasizes in [34] that the COVID-19 pandemic and the often devastating and lethal post-infection complications illustrate today's highly incomplete understanding of the pathophysiological consequences of immune responses to the virus. He outlines three critical sets of issues that need to be pursued to help control the virus pandemic:

1) Determining the strength and durability of immune response to the virus, which would clarify whether re-infection is likely and when, and just how long does a person really remain infectious even if asymptomatic;

2) Explaining the differences that contribute to startlingly different courses of disease with some patients recovering quickly and without many or any apparent complications while others develop very severe respiratory symptoms and succumb even when on ventilator devices. Early results from The Netherlands and France have implicated a specific gene TLR7 which, when deleted, led to type I interferon expression being blunted, with the consequence of severe disease ensuing;

3) The possibility of autoimmune diffuse symptoms being triggered by a SARS$\mathrm{CoV}-2$ infection affecting the brain, heart, and other organs, as well as producing blood-clotting for reasons presently not understood.

Thus, even with the wealth of new insights about viral and other microorganism mechanisms within cells, and their impact on immunology and vaccine development [48], these insights have not yet translated into enough discoveries about their effects at the tissue and organ levels to help understand the physiological consequences of Covid-19 in a way that can bridge biomechanistic with statistical observations in the many courses of illnesses and their complications that SARS can take. Governments and health institutions worldwide were unready to cope with SARS-CoV2 ahead of time [49, 50]. So, to try to contain the spread of the disease they had to depend primarily on traditional social measures relying on individual compliance: use of masks or other types of personal protective equipment (PPE), such as face shields for all, and body suits for practitioners in direct contact with ill patients, and behaviors such as maintaining social distancing to minimize exposure of self and others, and avoidance of large, dense gatherings, since many people might be asymptomatic carriers and potential disease-spreaders whose numbers can, at this point, only be guessed at, given the very dynamic and poorly documented evolution of the pandemic as new variants of the virus continue to be discovered [51].

From a public health informatics perspective, a variety of decision support systems have been developed to identify high-risk areas for zoonotic disease outbreaks [52], as have web-based tools for summarizing the information about the pandemic spread [53]. In healthcare informatics there is a long history of computer-based clinical decision support systems, or CDSSs [54], many developed with $\mathrm{AI}$ techniques over the past 50 
years [55]. A wide range of these CDSSs are linked to electronic health records (EHRs) which provide some degree of improvement in clinical process outcomes [56], but they are unable to help with clinical management of the novel and poorly-understood viral infections like COVID-19 for which critical data on the spectrum of disease progression, outcomes, and comorbidities is still lacking. Only after the current pandemic has abated will it be possible to discover the critical epidemiological factors about how quickly and for how long does immunity persist after a person recovers from COVID-19, and whether and for how long they might remain contagious, as well as understanding of viral load and transmission effects on type and severity of disease, and correlation of these with immune reactions in individuals of different age, gender, and ethnic groupings all of which requires ongoing investigations [57]. As result of the above limitations, public health measures continue to rely on applying general population-level travel restrictions together with requested quarantining of suspected infectious individuals or those who may have been exposed, especially if they have travelled from "hot spots" in the outbreak. These, restrictions, however, have been applied relatively haphazardly by different governments at different times responding to national socio-political-economic pressures. The many countries and regions where quarantining is optional or not enforced even when required, means that these measures are likely to be largely ineffective in controlling the pandemic worldwide given the unreliability, frequent indifference, and even risk-seeking of many people.

The development of vaccines benefiting from bioinformatics methods and genomic data and knowledge, on the other hand, has been proceeding at an unheard-of pace. Whereas traditionally it has taken two to four years to develop a vaccine (if this proves possible at all), for COVID-19 by November 2020 successful results in remarkably rapid vaccine trials have been reported [58], with a spectrum of vaccines having different properties in terms of mechanisms of action and requirements for delivery. The multiple phases of testing needed to estimate subgroup-specific efficacy means that it will take some time before reliable data are available to compare and assess the candidate vaccines [59]. This is of especial concern in terms of differential impact in different subpopulations, especially since so many people and their political leaders have downplayed the severity of the pandemic's threat to health, with resulting mortality rates being considerably above the expected numbers as seasonally adjusted deaths are becoming quite significant as of this writing in early 2021. As result, there is an increasing call for better communication and even compulsory behavioral controls, such as heavy fines for non-mask wearing in locations of major infection, and lockdowns of businesses, schools, and other public venues. Reminders of the historically well-attested deadliness of the influenza pandemic after World War I [60] do not seem to have persisted in popular historical memory enough to have had an influence in developing riskaverse behaviors in people who are routinely used to much milder seasonal influenza outbreaks - ignoring the fact that these can also be highly risky and fatal when new strains appear, such as those of Swine Flu [61].

A gripping and detailed description of how the current COVID-19 pandemic unfolded in its early phases (up to about August 2020), eloquently covering the many worldwide missteps in the responses to it, and the extremely disruptive and often lethal impacts on health and all aspects of life in societies around the globe can be found in the book by the physician and sociologist Nicholas Christakis [62].

\section{Data Infrastructure and Informatics for Pandemics and Developing Vaccines in the Age of Genomic Epidemiology}

Public health was the motivation for some of the earliest systems for medical documentation in the $19^{\text {th }}$ century, and computer-based healthcare-related informatics developed after World War II [63]. Public health is aimed at maintaining good health and preventing disease in communities, regions, and countries, and as such is closely related and dependent for its analytical methods on epidemiology, which studies the incidence, prevalence, and determinants of injury, disability, and disease in populations [64]. Epidemiology in turn, has benefited over the years from considerable experience in the application of statistical methods based on demographics, and the ways in which populations can be stratified and analyzed in observational studies and experiments designed for controlled studies of medical interventions in healthcare situations ranging from the clinical to the introduction of vaccination or other preventive measures through programs at regional and national levels throughout the world [65].

Because of the great diversity of mutagenic pathogens which can lead to pandemics [66], records of the different infectious disease outbreaks now include their detailed genomic epidemiological variants from the rapid whole-genome sequencing methods and the bioinformatics analytics constantly being improved and used in surveillance systems [67]. Genomic epidemiology is defined as "the use of pathogen genome sequencing to understand infectious disease transmission and epidemiology" and with results obtained directly from clinical samples in real time, the promise of personalizing molecular diagnoses is on the horizon [68]. Yet, developing adequate data infrastructures for supporting such genomic epidemiology at scale for public health purposes has lagged behind the research advances and their usually siloed databases which are frequently unavailable - as are the methodologies, especially those used by private companies.

With the COVID-19 pandemic responsible for rapid and unexpected spread of infections, deaths, overwhelming of medical facilities, and lockdowns of societies and their economies in early 2020, the U.S. National Academies were tasked to produce a Consensus Study Report on the Genomic Epidemiology Data Infrastructure Needs, subtitled Modernizing Pandemic Response Strategies [69]. The first highlighted conclusion is that "Current sources of SARS-CoV-2 genome sequence data, and current efforts to integrate these data with relevant epidemiological and clinical data, are patchy, typically passive, reactive, uncoordinated, and underfunded in the USA". The report points out 
how available data were unrepresentative, biased, and inadequate to answer questions about viral evolution and transmission, and, most importantly, how genome sequence variants might be related to virulence, pathogenesis, clinical outcomes, and the effectiveness of countermeasures. These inadequacies in data infrastructure that were needed to prepare for the COVID-19 pandemic, vividly demonstrate the failure of those (mainly political appointees) in charge of public health in the USA to heed the warnings of experts and learn from those who led the very (relatively recent) successful efforts in controlling the earlier SARS and Ebola pandemics before they could spread widely and intensely worldwide.

The report from the National Academies [69] lists a number of data sources and initiatives for SARS-CoV-2, within the USA and internationally. These included the U.S. Centers for Disease Control and Prevention's (CDC's) SARSCoV-2 Sequencing for Public Health Emergency Response, Epidemiology, and Surveillance (SPHERES) consortium, coordinating a large-scale nationwide genomic sequencing effort across the United States and the National Center for Biotechnology Information (NCBI) at $\mathrm{NIH}$ as primary repository for all genomic sequencing. A major international effort is the Global Initiative on Sharing All Influenza Data (GISAID) now adapted to include SARS-CoV-2 data to record how viruses evolve and spread during outbreaks. Nearly every major SARS-CoV-2 study uses GISAID. The Nextstrain software tool is an open-source platform for exploiting the potential of genomic data from a variety of infectious disease pathogens to support epidemiological research and outbreak response with a GISAID-enabled interface of publicly available sequence data from every continent. It has powerful analytic and visualization tools for exploring data at various scales (e.g., global, continent, country, region), identifying major clades of the virus. Nextstrain can address questions about which regions of the genome are most variable, estimate the rate of infection, and identify sequences on the phylogenetic tree by features such as gender and age of those infected. The National COVID Cohort Collaborative (N3C) gathers clinical data for carrying out translational informatics research. International initiatives include the Global Alliance for Genomics and Health for genomic data sharing within a human rights framework; the COG-UK in the United Kingdom to guide health interventions and policies; the European COVID-19 Portal for rapid collection and sharing of genomic data; Galaxy COVID-19 for compiling best practices, infrastructure, and workflows to support genomic analyses of SARSCoV-2 data; and the Public Health Alliance for Genomic Epidemiology, a global coalition working to develop consensus standards, share best practices, and advocate for open science and data sharing in public health microbial bioinformatics.

The application of bioinformatics tools for research on COVID-19 is comprehensively described in [70], listing methods and software available for fast sequence detection and annotation, providing access to pandemic-related literature, and data to assist research and drug design. Covidex [71], an AI neural ranking model using a keyword search infrastructure designed to compete in the TREC-COVID text retrieval challenge over COVID-relevant literature in the open research dataset compiled by the Allen Institute for AI (AI2) is one of many references involving advanced bioinformatics approaches. Others include the web application Pangolin [72] which uses a dynamic nomenclature scheme for assigning global outbreak lineages, COPASI [73] for modelling the dynamics of pandemics, COVIDSIM [74] for building epidemiological models of viral spread (which had a strong political impact on UK policy in the decision to implement school and other lockdowns) [75], and CoV-GLUE [76] for tracking accumulating nucleotide changes. With these and the many other systems, apps, and software referenced in [70], the article makes a strong point about the critical need for better metadata to help coordinate and integrate all the bioinformatics tools in a coherent way. This results from the frequent inconsistencies that invariably arise from an overabundance of possible choices of different assumptions, parameter settings, and bioenvironmental and societal population constraints - potentially with many confounding variables. Models designed to interpret and predict different outcomes from the wide range of available methods for analyzing data are discussed in
[77]. Many are based on mathematical models for infectious disease spread [78], which date back to the 1920's [79], with recent systems incorporating insights from genomic science and bioinformatics methods for epidemiological modeling and analysis [80].

In the European Union, the coordination of strategies for vaccine development and public health among the member nations was announced by the European Commission in November 2020 [81]. Six contracts were concluded to allow the purchase of a vaccine with the pharmaceutical companies AstraZeneca, Sanofi-GSK, Johnson \& Johnson, BioNTech-Pfizer, Curevac, and Moderna. AstraZeneca's vaccine candidate, developed in collaboration with Oxford University, already entered large-scale Phase II / III clinical trials after achieving promising Phase I / II results in safety and immunogenicity by the fall of 2020. The agreement was financed with the Emergency Support Instrument, and the Commission continues discussing similar agreements with other vaccine manufacturers. A contract between Sanofi-GSK and the European Commission entered into force following the contract's formal signature, and once proven to be safe and effective against COVID-19, the contract will allow all EU Member States to purchase up to 300 million doses of the vaccine. Sanofi and GSK also indicated they will try to provide a significant portion of their vaccine supply through a collaboration with the COVID-19 Vaccines Global Access facility, or COVAX [81] which has been developed by the Global Alliance for Vaccines (GAVI), the Coalition for Epidemic Innovations (CEPI), and the World Health Organization (WHO) to provide access to the COVID-19 ACTS Tools Accelerator to all people in a timely manner, but with lower and middle-income countries especially in mind.

BioNTech-Pfizer and Moderna have produced a new class of vaccines based on microRNA [82], which acts as a data carrier and informs the body on how to make proteins that trigger immunity to COVID-19, although having difficulties of preservation and transportation issues due to the ultra-low temperatures needed for maintaining vaccine efficacy. The development and deployment of medical informatics studies, as well as apps and systems for dealing with the COVID-19 
pandemic have been rapid and extensive [84-87], while facing problems of acceptance and mistrust, especially when dealing with problems of contact-tracing [88]. Professional societies in healthcare informatics have supported these informatics efforts [42,89]. Ethical challenges faced by informatics for public health are discussed in [90], where three main themes are covered: (1) public health reporting and data sharing, (2) contact tracing and tracking, and (3) clinical scoring tools for critical care, with corresponding proposed actionable recommendations for broader change beyond the pandemic for public health organization and policy reform. Non-standardized, ad-hoc reporting and inadequate coordination and integration of data across administrative boundaries are identified as major causes of failure in public health responses, and while the value of tracing infections is undeniable, the automated (often covert or undisclosed) tracking of patients and their contacts for enforcing quarantines or other restrictions has significant potential for privacy abuse by authorities [91,92]. The recommendations for clinical scoring of patients with severe COVID-19 disease in ICUs involved the need to incorporate such tools as integral components for critical care to help with decisions for admission triage, ventilator allocation, and cardiopulmonary resuscitation [93]. At the same time the authors point out the inadequacies of many scoring algorithms which do not take into account changes in resource-availability, patient preferences, or disability factors with comorbidities.

In the United States, inadequacies in response to the pandemic have been widely reported to result from deliberate policy by politicians and their appointees who chose to pay no attention to the warnings, and then hobbled the Center for Disease Control and Prevention (CDC) - the lead US agency for gathering and analyzing epidemiological data and coordinating epidemic countermeasures - while systematically denying the severity and even the existence of a pandemic in its first months of recorded spread across the world. The scientific and hospital data collection and tracking systems previously professionally managed by the CDC were switched to a private company with the stated reason being that the $\mathrm{CDC}$ pointed out that providing $100 \%$ of hospital data daily from the heterogenous distributed sources would be difficult [94]. The American Medical Informatics Association issued an Open Letter protesting against these actions and making recommendations to stay with the well-tested public systems of the CDC [95]. On the other hand, the provision of considerable funding from the US Congress through the CARES Act for a number of emergency measures to counter the pandemic, including the rapid development of vaccines under the title of "Operation Warp Speed" proved to be very successful in helping stimulate unexpectedly rapid vaccine development and funding badly needed supplies such as respirators and other hospital equipment and medications, even though the political factors had a strong effect on competing pandemic containment strategies [96]. Meanwhile, the WHO received the support of Bill Gates, who worked with drug manufacturers and provided funding through the Gates Foundation to speed up vaccine development [97]. In South Asia, issues of policy implementations and difficulties with resources accounted for highly differing outcomes in different countries [98]. Africa had very few cases of COVID-19 reported early in the pandemic, possibly attributable to the many fewer connections to the rest of the world in its equatorial zone, with populations considerably more dispersed than in other world regions, more impacted with malaria endemically, and with less diabetes and heart disease. All of these problems have contributed to difficulties in tracking the pandemic despite sophisticated geospatial modeling with satellite data [99].

\section{Historical Cultural Norms for Hygiene and Public Health: The Problem of Unreliable Humans}

The history of pandemics illustrates how, like with all catastrophic natural disasters, humans as members of groups and societies exhibit a wide range of behaviors in adhering to social norms and acting rationally cooperatively or not with other members of their group, as studied cross-culturally in the context of evolutionary game theory models recently [100], or introduced with cross-species-oriented popular arguments for evolutionary development of trust among humans [101]. In terms of public health from ancient times, one can note early efforts to ensure cleanliness of environments and uncontaminated water supplies [102], as well as distinct behavioral roles for individuals - traditionally women - who devoted their lives to healing and health-caring duties [103]. These are best known in the West as developing into the religious orders of sisters or brothers, whose members administered medications and nursed the sick adhering to standards of caring for others as often enunciated in their vows [104]. The influence of Hippocratic rational medical traditions in the Hellenistic Middle East, its admixture with traditional religious practices, and diffusion through the Roman empire is discussed in Kottek and Horstmanshoff [105]. Strong awareness of the central importance of personal hygiene, public or group practices of washing, and relationship to religious rituals for purification or cleansing upon entry into temples or homes is known in almost all major cultures, in the East especially from the Buddhist traditions in India and China [106], and in the Islamic, Sikh, and other world religious traditions [107]. These issues of cleanliness and religion are considered as part of the $\mathrm{WHO}$ guidelines on Hand Hygiene in Health Care [108]. The argument has also been made that the need for personal hygiene precedes human history and has evolved from very early in animal species evolution through beneficial effects of adaptive behaviors, and in humans specifically to avoid infectious diseases [109]. For the current worldwide spread of COVID-19, the application of social and behavioral science approaches to assist in responding to the pandemic is discussed in [110].

In the US literature, the history of public health from ancient to modern times was first covered most notably by Rosen [111] in his monumental and comprehensive book from 1958, in which he took a progressive, highly socioeconomic-centered perspective towards educating practitioners of the field about the antecedents of their discipline. He describes the impact on population health in the $19^{\text {th }}$ century following dislocations during and after the Napoleonic Wars, resulting 
from rapid advances in industrialization, commerce, science, and technology (especially for transport, lighting, and heating), which all led to unprecedented scales of crowding in cities with primitive sanitation, encouraging epidemic disease which could not be ignored. This spurred European and American physicians and scientists to search for the underlying causes, resulting in the bacteriological discoveries of Pasteur and Koch. They also led to the emphasis on clean water supplies and adequate sewage disposal and treatment, or the highly influential "sanitary idea" and the gathering of systematic statistical data on living and health conditions, primarily in France and in Britain, where the clear correlation between wealth and health was demonstrated [112]. At the same time, hygienic, medical, and nursing practices for the control of sepsis or infection in hospitals and surgeries were gradually implemented following Semmelweis' demonstrations that hand washing prior to delivery of infants was critical to avoid postnatal fevers and maternal infection and death [113] - basic procedures which are still the mainstay of contagion prevention today. The role of contamination of water supplies during cholera epidemics in London was demonstrated by John Snow, whose On the Mode of Communication of Cholera led to the recognition that it was not person-to-person transmission or miasmas in the polluted air that caused the disease. The importance of worker health for competitive industrial economies, and of military health for their armies led to many improvements in healthcare practices, and much social change. These both combined in the remarkable successes by Florence Nightingale (whose birth bicentenary was celebrated in 2020 as the Year of the Nurse) for dramatically improving military hospital sanitation during the Crimean War, turning nursing into an effective and essential healthcare profession that was respectable [114]. In relation to informatics "her contribution to statistical thought, particularly applied to healthcare, was astonishing. She, for example, was the first person to use pie charts in health sciences. She used pie charts for a reason. They fulfilled her belief that statistical data should be easily accessible to the average intelligent person. She liked to apply what she called privately "the Queen Victoria test". She would look at a diagram- matic representation of data and ask herself would The Queen understand the point that was being made by the data" [115]. Considering the difficulties, we still face in today's age of data science for visualizing the impact of COVID-19 on society through summarizing statistical illustrations that laypersons can understand, hers was a pioneeringly relevant achievement that deserves to be much better known and recognized than it is. Nightingale also asked the Belgian statistician Quetelet, founder of the behavioral sciences [116], about possible ways of quantitating malnutrition - and he came up with the Body Mass Index, which is still used today, though usually for measuring the opposite effect: obesity.

Improvements in public health from the end of the $19^{\text {th }}$ through the $20^{\text {th }}$ century were set back by the global disasters of the first and second World Wars, including the sharp recurrence of humanity's old plague of tuberculosis (TB) [117] and the "Spanish Flu" pandemic from 1918-1919 which saw about 500 million people infected, and 50 million deaths, making it the most widespread pandemic of the modern era [118]. The world wars, however, also gave greater urgency to biomedical research, and accelerated medical discoveries for controlling infections through antibiotics [119] and trauma care methods [120], as well as the vaccination developments mentioned earlier. In consequence the current major challenge to pandemic control or amelioration remains human behavior which is unpredictably unreliable.

\section{Conclusion: Pandemic Workarounds for Behavioral Unreliability - Informatics and Education Based on Scientific Discoveries and Biotechnologies}

Pandemics throughout history have been and continue to be among the most devastating and unpredictable challenges faced by humankind. The reactions of people have invariably proven confused and wanting, even today with the biomedical scientific and technological advances outlined in this article. Education with up-to-date information about infectious diseases, their transmission, and control over the past 200 years, has strived to enlighten and encourage rational behavioral reactions to crises and disasters in all their forms including public health and pandemic events, and higher degrees of education among populations do seem to accomplish this [121]. Yet, the experiences of governments and other organizations during the current COVID-19 pandemic are hardly encouraging, and so there have been increasingly urgent calls by enlightened medical authorities emphasizing the need to better inform people about how to continue observing best behavioral practices to preserve public health so as to avoid the most restrictive and economically damaging social measures such as lockdowns - since, despite the rapid development and expected availability of vaccines, human behavioral unreliability will still enable contagion for some time before vaccination becomes sufficiently effective without relying on the non-plan of unethical disregard for public health measures in the expectation that natural herd immunity will be achieved [122]. In a keynote addressed to the American Informatics Association, Dr. Anthony Fauci, director of the National Institute of Allergy and Infectious Diseases (NAID) not surprisingly emphasized the key role that informatics plays in the production and dissemination of scientific knowledge and of information that will encourage needed public health practices [123]. It is in this sense that the biotechnologies of vaccination and informatics have been serving - and will continue to serve - as workarounds for the unreliability of human behaviors in managing the complex personal and societal decisions and actions that pandemics impose on people.

This places biomedical informatics during pandemics at a critical ethical center of debates about the tradeoffs between the degree to which Hippocratic practices ought to be adhered to by physicians, nurses, and healthcare practitioners, and the challenges of taking responsibility for decisions and actions involving human trust when automated systems in the rapidly developing Internet of Things (IoT) and AIs routinely 
augment or replace human interventions. Calculating, conscious humans always consider gains/losses for individuals vs. groups or populations in their thinking, and machines without responsibility are easily programmed to intentionally or unintentionally deceive, as experiences with social media demonstrate daily and have been most notoriously deployed politically in recent years in and by many countries around the globe [124]. In efforts to contain the COVID-19 epidemic, the "Anti-Vaxxer" movement [125] and its political supporters can be seen as especially harmful. For the care of the suffering and dying, urgent new lines of inquiry into human-machine roles and their ethical consequences within the contexts of relationships within this "Brave New World of AIs and the IOT" will be essential in order to understand what might be the most ethical design and use constraints for future Internets of People and Things that consider the Hippocratic dicta seriously. Insights into the distribution of responsibilities might then be employed to design strategies of persuasion that could convincingly encourage and guide enough people to live up to what the founder of cybernetics, Norbert Weiner, described as the Human Use of Human Beings [126].

In summary, the advances in scientific and technological insights have significantly improved understanding of infectious disease processes, in turn helping to mitigate devastating zoonotic infectious pandemics. SARS-CoV-2 is accelerating the design of data and informatics methods and systems, so that the best biomedical knowledge and clinical practices can help develop improved diagnostic, prognostic, and therapeutic methods which in the future may be able to increase personalization in the prevention and treatment of disease. Regretfully, however, past and present responses to pandemics have proved inadequate and ill organized. There is no plan to prepare for inevitable future epidemics as summarized vividly by Osterholm [127], who illustrates the difficulty of finding well-versed and perseverant leaders who will have a presence that commands attention from the general public to adopt behaviors that protect all of society. Consequently it is technologies that must serve as workarounds.

\section{Acknowledgements}

The author wishes to thank his friends and colleagues Dr. Victor Maojo and Dr. Jack Smith and the editors of the IMIA Yearbook of Medical Informatics for reading and commenting on an earlier version of this article, suggesting many improvements. All remaining shortcomings are entirely the author's responsibility.

\section{References}

1. Institute of Medicine (US) Forum on Emerging Infections; (Burroughs T, Knobler S, Lederberg J, editors). The Emergence of Zoonotic Diseases: Understanding the Impact on Animal and Human Health: Workshop Summary. Washington (DC): National Academies Press (US); 2002.

2. Martin PVM, Martin-Granel E. 2,500-year Evolution of the Term Epidemic. Emerg Infect Dis 2006 Jun;12(6): 976-80.

3. Hippocrates. Of the Epidemics (Adams F, Translation). Online Version: http://classics.mit.edu/ Hippocrates/epidemics.1.i.html

4. Thucydides. The History of the Peloponnesian War (Crawley R, Transl.), Project Gutenberg eBook Online Version: https://www.gutenberg. org/files/7142/7142-h/7142-h.htm

5. Longrigg J. Epidemic, Ideas, and Classical Athenian Society. In: Ranger T, Slack P, editors. Epidemics and Ideas: Essays on the Historical Perception of Pestilence. Cambridge Univ Press; 1987. p. 21-44.

6. Adamson PB. Human Diseases and Deaths in the Ancient Near East. In Die Welt des Orients 1982;13:5-14. Available from: https://www.jstor. org/stable/25683045

7. Habicht ME, Eppenberger PE, Rühli F. A critical assessment on proposed outbreaks of plague and other epidemic diseases in Ancient Egypt. Int J Infect Dis 2021;103:217-9. Epub 2020 Nov. Available from: https://doi.org/10.1016/j. ijid.2020.11.160

8. Souilmi Y, Lauterbur ME, Tobler R, Huber CD, Johar AS, Enard D, An ancient coronavirus-like epidemic drove adaptation in East Asians from 25,000 to 5,000 years ago. BioRxiv [Preprint]. [posted Jan 2021]. Available from: https://www. biorxiv.org/content/10.1101/2020.11.16.38540 1v1.full.pdf $+h t m l$

9. Dawson WR, Harvey FD. Herodotus as a medical writer, Bull Inst Class Stud Univ Lond 1986;33:87-96

10. Kalisch BJ. Of half-gods and mortals: Aesculapian authority. Nursing Outlook 1975; 23(1):22-8. Available from: http://www. truthaboutnursing.org/images/kalisch/half_ gods_and_mortals.pdf

11. Shmerling RH. First Do No Harm. In: Harvard Health Blog [Internet]. 2015 Oct 14. Available from: https://www.health.harvard.edu/blog/firstdo-no-harm-201510138421

12. Jotterand F. The Hippocratic Oath and Contemporary Medicine: Dialectic Between Past
Ideals and Present Reality? J Med Philos 2005;30(1):107-28.

13. Van der Eijk P, editor. Egyptian medicine and Greek medicine. In: Jouanna J, Alies N. Greek Medicine from Hippocrates to Galen: Selected Papers. Leiden, Boston: Brill; 2012. p. 3-20 [cited 2020 Nov 20]. Available from: www.jstor. org/stable/10.1163/j.ctt1w76vxr.6

14. Kannadan A. History of the Miasma Theory of Disease. ESSAI 2018;16: Article 18. Available from: https://dc.cod.edu/essai/vol16/iss1/18

15. Tountas Y. The historical origins of the basic concepts of health promotion and education in ancient Greek philosophy and medicine. Health Promot Int 2009;24(2):185-92.

16. Papagrigorakis MJ, Yapijakis C, Synodinos PN, Baziotopoulou-Valavani E. DNA examination of ancient dental pulp incriminates typhoid fever as a probable cause of the Plague of Athens. Int $\mathrm{J}$ Infect Dis 2006;10(3):206-14.

17. Davis S. Solving the Mystery of an Ancient Epidemic. The Atlantic; September 15, 2015.

18. Wasson DA. Galen. In: Ancient History Encyclopedia [citec 2020Nov 20]. Available from: https://www.ancient.eu/Galen/

19. Harper K. The Fate of Rome: Climate, Diseases, and the End of an Empire. Princeton: Princeton University Press; 2017.

20. Russell JC. That earlier plague. Demography 1968;5:174-84.

21. Dols MW. Plague in Early Islamic History. J American Oriental Soc 1974; 94(3):371-83.

22. Keller M, Spyrou MA, Scheib CL, Neumann GU, Kröpelin A, Haas-Gebhard B, et al. Ancient Yersinia pestis genomes from across Western Europe reveal early diversification during the First Pandemic (541-700). Proc Nat Acad Sciences 2019;201820447. DOI: 10.1073/ pnas. 1820447116.

23. Mordechai M, Eisenberg M, Newfield TP, Izdebski A, Kay JE, Poinar H. The Justinianic Plague: An inconsequential pandemic? Proc Nat Acad Sciences 2019;116(51):25546-54.

24. Miller TS. The Birth of the Hospital in the Byzantine Empire. Baltimore: Johns Hopkins Univ Press; 1997.

25. Risse GB. Mending Bodies, Saving Souls: A History of Hospitals. Oxford: Oxford Univ Press; 1999.

26. Oldstone MBA. Viruses, Plagues, \& History. Oxford: Oxford Univ Press; 2010

27. Cohn SK. Cultures of Plague: Medical Thinking at the end of the Renaissance. Oxford Scholarship Online; February 2010.

28. Pullan B. Plague and perceptions of the poor in early modern Italy. In: Ranger T, Slack P, editors. Epidemics and Ideas: Essays on the Historical Perception of Pestilence. Cambridge Univ Press; 1987. p. 101-23.

29. Diamond J. Guns, Germs, and Steel: The Fates of Human Societies. New York: W.W. Norton; 1997.

30. Gaynes RP. Germ Theory: Medical Pioneers in Infectious Diseases. New York: Wiley; 2011.

31. Kinch M. Between Hope and Fear: A History of Vaccines and Human Immunity. New York and London: Pegasus Books; 2018.

32. Riedel S. Edward Jenner and the history of smallpox and vaccination. Proc Baylor Univ Med 
Cent 2005;18(1):21-5.

33. Debré P. Louis Pasteur. Translated by Forster, Elborg. Baltimore: JHU Press; 2000.

34. Mukherjee S. Before Virus, After Virus: A Reckoning. Cell 2020;183(2):308-14.

35. Graeber C. The Breakthrough: Immunotherapy and the Race to Cure Cancer. New York: Twelve, Hachette Book Group; 2018.

36. Shope RE. Pathogenesis and Virulence of Zoonotic Infections in Humans. In: Institute of Medicine (US) Forum on Emerging Infections; Burroughs T, Knobler S, Lederberg J, editors. The Emergence of Zoonotic Diseases: Understanding the Impact on Animal and Human Health: Workshop Summary. Washington (DC): National Academies Press (US); 2002.

37. Chinese SARS Molecular Epidemiology Consortium. Molecular evolution of the SARS coronavirus during the course of the SARS epidemic in China. Science 2004;303(5664):1666-9.

38. Guan Y, Zheng BJ, He YQ, Liu XL, Zhuang $\mathrm{ZX}$, Cheung $\mathrm{CL}$, et al. Isolation and characterization of viruses related to the SARS coronavirus from animals in Southern China. Science 2003;302 (5643):276-8.

39. Kan B, Wang M, Jing H, Xu H, Jiang X, Yan $\mathrm{M}$, et al. Molecular evolution analysis and geographic investigation of severe acute respiratory syndrome coronavirus-like virus in palm civets at an animal market and in farms. J Virol 2005;79(18):11892-900.

40. https://www.nlm.nih.gov/

41. https://en.wikipedia.org/wiki/National_Center_for_Biotechnology_Information

42. Bakken S. Informatics is a critical strategy in combating the Covid-19 pandemic. J Am Med Inform Assoc 2020 Jun;27:6:843-4.

43. Ye Q, Zhou J, Wu H. Using Information Technology to Manage the COVID-19 Pandemic: Development of a Technical Framework Based on Practical Experience in China. JMIR Med Inform 2020 Jun 8;8(6):e19515.

44. Wilson C, Gabrielsen Jumbert M. The new informatics of pandemic response: humanitarian technology, efficiency, and the subtle retreat of national agency. J Intern Humanitarian Action 2018;3(1):1-13.

45. https://www.who.int/standards/classifications/ classification-of-diseases/emergency-use-icdcodes-for-covid-19-disease-outbreak

46. http://hl7.org/fhir/2020May/icd.html

47. Sivashankaran S, Borsi JP, Yoho A. Have ICD-10 Coding Practices Changed Since 2015? AMIA Annu Symp Proc 2020 Mar 4;2019:804-11. eCollection 2019.

48. Nandy A, Basak SC. Bioinformatics in Design of Antiviral Vaccines. Encyclopedia of Biomedical Engineering 2019:280-90.

49. Sternfeld J. Unprepared: America in the Time of Coronavirus. Kindle Edition; 2020.

50. Goodman PS, Pianigiani G. Why Covid Caused so much suffering in Italy's Wealthiest Region. New York Times; Nov 19, 2020.

51. https:/www.who.int/csr/don/31-december-2020sars-cov2-variants/en/

52. Beard R, Wentz E, Scotch M. A systematic review of decision support systems in public health informatics supporting the identification of high risk areas for zoonotic disease outbreaks. Int J Health Geogr 2018 Oct 30;17(1):38.

53. Dong E, Du H, Gardner L. An interactive webbased dashboard to track Covid-19. Lancet Infect Dis 2020 May;20(5):533-4.

54. Middleton B, Sittig DF, Wright A. Clinical Decision Support: A 25 year Retrospective and a 25 Year Vision. Yearb Med Inform 2016;25(S01): S103-S116.

55. Kulikowski CA. Beginnings of Artificial Intelligence in Medicine (AIM): Computational Artifice Assisting Scientific Inquiry and Clinical Art-with Reflections on Present AIM Challenges. Yearb Med Inform 2019:249-56.

56. Kwan JL, Lo L, Ferguson J, Goldberg H, Diaz-Martinez JP, Tomlinson G, et al. Computerised clinical decision support systems and absolute improvements in care: meta-analysis of controlled clinical trials. BMJ 2020;370m 3216.

57. Cevik M, Tate M, Lloyd O, Maraolo AE, Schafers J, Ho A. SARS-CoV-2, SARS-CoV, and MERS-CoV viral load dynamics, duration of viral shedding and infectiousness: a systematic review and metanalysis. Lancet Microbe 2021 Jan;2(1):e13-e22.

58. Cohen J. Vaccine wagers on coronavirus surface protein pay off. Science 2020;370(6519):894-5.

59. Lipsitch M, Dean NE. Understanding Covid-19 vaccine efficacy. Science 2020;370(6518):763-5.

60. Toney JH, Ishack S. A Pandemic of Confusion: Conflicting messages have characterized not just COVID-19 but also many past disease outbreaks. American Scientist 2020;108(6):344-8.

61. https://medlineplus.gov/h1n1fluswineflu.html

62. Christakis NA. Apollo's Arrow: The Profound and Enduring Impact of Coronavirus on the Way We Live. 2020. Little, Brown Spark, Hachette Book Group, New York.

63. Collen MF, Lehmann HP. Public and Personal Health Testing Systems, in The History of Medical Informatics in the United States. Collen MF, Ball MJ, editors. London: Springer-Verlag; 2015.

64. LaVenture M, Ross DA, Yasnoff WA. Public Health Informatics. In: Shortliffe EH, Cimino J, editors. Biomedical Informatics: Computer Applications in Health Care and Biomedicine (4th Edition) London: Springer-Verlag; 2014.

65. Szklo M, Javier Nieto F. Epidemiology: Beyond the Basics (3rd Edition). Burlington, MA: Jones \& Bartlett Learning; 2014.

66. Glanz J, Carey B. Beech H Evidence builds that an early mutation made the pandemic harder to stop. New York Times; November 25, 2020. Available from: https://nyt.ms/3pV0ngz

67. Gardy JL, Loman NJ. Towards a genomics-informed, real time, global pathogen surveillance system. Nat Rev Genet 2018;19(1):9-20.

68. Houldcroft CJ, Beale MA, Breuer J. Clinical and biological insights from viral genome sequencing 2017. Nat Rev Microbiol 2017;15(3):183-92.

69. National Academies of Sciences, Engineering and Medicine Consensus Study Report. Genomic Epidemiology Data Infrastructure Needs for SARS-CoV-2: Modernizing Pandemic Response Strategies. Washington, DC: National Academies Press; 2020.

70. Hufsky F, Lamkiewicz K, Almeida A, Aouacheria A, Arighi C, Bateman A et al. Computational
Strategies to combat COVID-19: useful tools to accelerate SARS-CoV-2 and coronavirus research. Brief Bioinform 2020 Nov 4:bbaa232

71. Zhang E, Gupta N, Tang R, Han X, Pradeep $\mathrm{R}$, Lu K, et al. Covidex: Neural Ranking Models and Keyword Search Infrastructure for the COVID-19 Open Research Dataset. arXiv:2007.07846v1 [cs.IR] [Preprint] [posted 2020 Jul 14].

72. Rambaut A, Holmes EC, O'Toole A, Hill V, McCrone JT, Ruis C, et al. A dynamic nomenclature proposal for SARS-CoV-2 lineages to assist genomic epidemiology. 2020. Nat Microbiol 2020;5(11): 1403-7.

73. Bergmann FT, Hoops S, Klahn B, Kummer U, Mendes P, Pahle J, et al. COPASI and its applications in biotechnology. J Biotechnol 2017;261:215-20.

74. Ferguson NM. Report 9: Impact of non-pharmaceutical interventions (NPIs) to reduce COVID-19 mortality and healthcare demand. Imperial College London; 2020. Available from: https://www.imperial.ac.uk/mrc-global-infectious-disease-analysis/covid-19/report-9-impactof-npis-on-covid-19/

75. Rice K, Wynne B, Martin V, Ackland GJ. Effect of school closures on mortality from coronavirus disease 2019: old and new predictions. BMJ 2020;Oct 7;371:m3588. Available from: https://doi.org/10.1136/bmj.m3588

76. Singer J, Gifford R, Cotton M, Robertson D. CoV-GLUE: A Web Application for Tracking SARS-CoV-2 Genomic Variation. Preprints.org. [Preprint] 2020, 2020060225. [posted 2020 Jun 17] Available from: https://www.preprints.org/ manuscript $/ 202006.0225 / \mathrm{v} 1$

77. Hutson M. The Next Pandemic: The Mess behind the models. Spectrum IEEE 2020 Oct:31-5.

78. Hethcote HW. The Mathematics of Infectious Diseases. SIAM Review 2000;42(4):599-653.

79. Kermack WO, McKendrick AG. A contribution to the mathematical theory of epidemics. Proc R Soc A 1927;115(772):700-21.

80. Gardy JL, Loman NJ. Towards a genomics-informed, real-time, global pathogen surveillance system. Nat Rev Genet 2018;19(1): 9-20.

81. European Commission. Coronavirus Response. November 2020. https://ec.europa.eu/info/ live-work-travel-eu/coronavirus-response/public-health_en

82. https://www.gavi.org/vaccineswork/covax-explained

83. Baden LR, El Sahly HM, Essink B, Kotloff K, Sharon Frey, Rick Novak, et al. Efficacy and Safety of the mRNA-1273 SARS-CoV-2 Vaccine. New England J Med 2020 Dec 30;NEJMoa2035389.

84. Wu H, Zhang H, Karwath A, Ibrahim Z, Shi T, Zhang X, et al. Ensemble learning for poor prognosis predictions: a case study on SARS-CoV2. J Am Med Inform Assoc 2020 Nov 13; ocaa295.

85. Scudeliari M. Hospitals Deploy AI tools to Detect Covid-19 on Chest Scans. IEEE Spectrum 2020.

86. McGhee K. Building surge capacity during Covid-19, Medical University of South Carolina News Center; July 7, 2020.

87. Tang PC, Miller S, Stavropoulos H, Kartoun U, Zambrano J, Ng K. Precision population analyt- 
ics: population management at the point-of-care. J Am Med Inform Assoc 2020 Nov 12; ocaa247.

88. Muscato L. Why people don't trust contact tracing apps, and what to do about it. MIT Technology Review, November 12, 2020.

89. Atique S, Bautista JR, Block LJ, Lee JJ, Lozada-Perezmitre E, Nibber R, et al. A nursing informatics response to COVID 19: Perspectives from five regions of the world. J Adv Nurs 2020 Oct; 76(10):2462-8.

90. Subbian V, Solomonides A, Clarkson M, Rhimzdeh N, Petersen C, Schreiber R, et al. Ethics and informatics in the age of COVID-19: challenges and recommendations for public health organization and public policy. J Am Med Inform Assoc 2021 Jan 15;28(1):184-9.

91. Wang CJ, Ng CY, Brook RH. Response to COVID-19 in Taiwan: Big Data Analytics, New Technology and Proactive Testing. JAMA 2020; 323(14) 1341-42.

92. Zuboff S. Big Other: Surveillance capitalism and the prospects of an information civilization. J Inf Technol 2015;30(1):75-89.

93. National Academies of Sciences, Engineering and Medicine. Rapid Expert Consultation on Crisis Standards of Care for the COVID-19 Pandemic. Washington, DC: National Academies Press; 2020.

94. Piller C. Undermining CDC: Deborah Birx, President Trump's Covid-19 coordinator, helped shake the foundation of a premier public health agency. Science 2020;370(6515):394-9.

95. AMIA: An Open Letter from the American Medical Informatics Association and the American College of Medical Informatics Regarding Public Health Reporting Deficiencies During the COVID-19 Pandemic. Sunday, July 19, 2020.

96. LaFraniere S, Thomas K, Weiland N, Gelles D, Stolberg SG, Grady D. Politics, Science, and the Remarkable Race for a Coronavirus Vaccine. New York Times, updated Nov 22, 2020.

97. Twohey M, Kulish N. Bill Gates, the Virus, and the Quest to Vaccinate the World, New York Times, Nov 23, 2020.

98. Sarkar A, Liu G, Jin Y, Zheng X, Zheng Z. Public health preparedness and responses to the COVID-19 pandemic in South Asia: A situation and policy analysis, Global Health J 2020 Dec;4(4):21-132.

99. Abbate J. COVID-19 in the African Continent: Biases and Obstacles to Tracking a Pandemic. GRAPH Network, Oct 30 Presentation, Sigma Xi Lecture; https://www.youtube.com/watch?v=-

\section{JB0PId4KJWI}

100. Roos P, Gelfand M, Nau D, Lun J. Societal threat and cultural variation in the strength of social norms: An evolutionary basis. Organizational Behavior and Human Decision Processes 2015;129:14-23.

101. Ridley M. The Origins of Virtue: Human Instincts and the Evolution of Cooperation. New York: Viking; 1997.

102. Wikipedia' History of Water Supply and Sanitation Systems. Available from: https:// en.wikipedia.org/wiki/History_of_water_supply_and_sanitation systems

103. Theofanidis D, Sapountzi-Krepia D. Nursing and Caring: An Historical Overview from Ancient Greek Tradition to Modern Times. Int J Caring Sciences 2015;8(3):791-800.

104. Amundsen DW. Medicine, Society, and Faith in the Ancient and Medieval Worlds. Baltimore: Johns Hopkins University Press; 1996.

105. Kottek S, Horstmanshoff HFJ, editors. From Athens to Jerusalem: Medicine in Hellenized Jewish Lore and in Early Christian Literature. Rotterdam, Netherlands: Erasmus Publishing; 2000.

106. Heirman A, Torck M. A Pure Mind in a Clean Body, Bodily Care in the Buddhist Monasteries of Ancient India and China. Academia Press; 2012.

107. Allegranzi B, Memish ZA, Donaldson L, Pittet D. Religion and Culture: Potential undercurrents influencing hand hygiene promotion in health care. Am J Infect Control 2009;37:28-34.

108. World Health Organization. WHO Guidelines on Hand Hygiene in Health Care: First Global Patient Safety Challenge Clean Care Is Safer Care. Geneva: WHO Publications; 2009.

109. Curtis VA. A natural history of hygiene. Can J Infect Dis Med Microbiol 2007 Jan;18(1):11-4.

110. Bavel JJV, Baicker K, Boggio PS, Capraro V, Cichocka A, Cikara M, et al. Using social and behavioural science to support COVID-19 pandemic response. Nat Hum Behav 2020;4:460-71.

111. Rosen G. A History of Public Health. Johns Hopkins Univ Press; 1958 (revised updated edition 2015).

112. A Brief History of Public Health. [cited 2020 Oct]. Available from: https://sphweb.bumc. bu.edu/otlt/mph-modules/ph/publichealthhistory/publichealthhistory 7.html

113. Noakes TD, Borresen J, Hew-Butler T, Lambert MI, Jordaan E. Semmelweis and the aetiology of puerperal sepsis 160 years on: an historical review. Epidemiol Infect 2008;136, 1-9.

114. Hundt B. Reflections on Nightingale in the Year of the Nurse. Am Nurse J 2020;15(5):26-9.

115. Horsley K. Florence Nightingale. J Military and Veterans Health 2010;18(4):4.

116. Jahoda G. Quetelet and the emergence of the behavioral sciences. Springerplus 2015 Sep 4;4:473.

117. Ryan F. The Forgotten Plague: How the Battle against Tuberculosis was Won - and Lost. Boston: Little Brown \& Co; 1992.

118. Taubenberger JK, Morens DM.1918 Influenza: the Mother of All Pandemics Emerg Infect Dis Jan 2006;12(1):15-22.

119. Aminov RI. A Brief History of the Antibiotic Era: Lessons Learned and Challenges for the Future. Front Microbiol 2010;1:134.

120. Foss J. A History of Trauma Care: From Cutter to Trauma Surgeon. AOR Journal 1989;50(1):213,26-8,30.

121. Hahn RA, Truman BI. Education Improves Public Health and Promotes Health Equity. Int J Health Serv 2015;45(4): 657-78.

122. Aschwanden $\mathrm{C}$. The false promise of herd immunity. Nature 2020 Nov;587(7832):26-8.

123. Fauci AS, Brennan PF. Fireside Chat with Dr. Anthony S. Fauci interviewed by Dr. Patricia Flatley Brennan - AMIA 2020 Annual Symposium: Special Plenary Session, Nov. 16, 2020.

124. Woolley SC, Howard PN, editors. Computational Propaganda: Political Parties, Politicians, and Political Manipulation on Social Media. New York: Oxford University Press; 2019.

125. Berman JM. Anti-vaxxers: How to Challenge a Misinformed Movement. Cambridge, MA: MIT Technology Press; 2020.

126. Wiener N. The Human Use of Human Beings: Cybernetics and Society. Boston: Houghton Mifflin; Revised Updated Edition 1954 (Da Capo Press paperback unabridged republication).

127. Osterholm MT, Olshaker M. Deadliest Enemy: Our War Against Killer Germs. New York: Little Brown Spark, Paperback updated edition; 2020.

Correspondence to:

Casimir A. Kulikowski

Department of Computer Science

Rutgers - The State University of New Jersey

Piscataway, NJ 08855, USA

E-mail: kulikows@cs.rutgers.edu 